\title{
A global-scale expert assessment of drivers and risks associated with pollinator decline
}

\author{
Lynn V. Dicks $\mathbb{1}^{1,2} \bowtie$, Tom D. Breeze ${ }^{3}$, Hien T. Ngo $\mathbb{1}^{4}$, Deepa Senapathi ${ }^{3}{ }^{3}$, Jiandong An ${ }^{5}$, \\ Marcelo A. Aizen (106, Parthiba Basu (107, Damayanti Buchori8,9, Leonardo Galetto ${ }^{10}{ }^{10,11}$, \\ Lucas A. Garibaldi ${ }^{12,13}$, Barbara Gemmill-Herren ${ }^{14,15}$, Brad G. Howlett ${ }^{16}$, Vera L. Imperatriz-Fonseca ${ }^{17}$, \\ Steven D. Johnson ${ }^{18}$, Anikó Kovács-Hostyánszki ${ }^{19}$, Yong Jung Kwon ${ }^{20}$, H. Michael G. Lattorff ${ }^{10}{ }^{21}$, \\ Thingreipi Lungharwo ${ }^{22}$, Coleen L. Seymour ${ }^{23,24}$, Adam J. Vanbergen ${ }^{25}$ and Simon G. Potts $\mathbb{B}^{3}$
}

\begin{abstract}
Pollinator decline has attracted global attention and substantial efforts are underway to respond through national pollinator strategies and action plans. These policy responses require clarity on what is driving pollinator decline and what risks it generates for society in different parts of the world. Using a formal expert elicitation process, we evaluated the relative regional and global importance of eight drivers of pollinator decline and ten consequent risks to human well-being. Our results indicate that global policy responses should focus on reducing pressure from changes in land cover and configuration, land management and pesticides, as these were considered very important drivers in most regions. We quantify how the importance of drivers and risks from pollinator decline, differ among regions. For example, losing access to managed pollinators was considered a serious risk only for people in North America, whereas yield instability in pollinator-dependent crops was classed as a serious or high risk in four regions but only a moderate risk in Europe and North America. Overall, perceived risks were substantially higher in the Global South. Despite extensive research on pollinator decline, our analysis reveals considerable scientific uncertainty about what this means for human society.
\end{abstract}

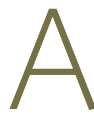
nimal pollination is key to the reproductive success of $>75 \%$ of flowering plants globally, including many culturally and economically important plants $^{1,2}$. Pollination services are estimated to add billions of dollars to global crop productivity and contribute to nutritional security ${ }^{3}$. Despite these multiple values, there is growing evidence of wild pollinator population declines ${ }^{4,5}$ and deficits in crop production due to insufficient pollination ${ }^{6}$, while global demand for pollination services is at an all-time high and likely to continue to grow ${ }^{8}$. Conversely, populations of managed honey bees, while declining in North America and parts of Europe, are increasing in many countries ${ }^{9}$. Observed trends in wild pollinators have been mostly linked with changes in land management ${ }^{10}$, climate change ${ }^{11}$ and agrochemical use ${ }^{12}$, although these analyses are largely restricted to Europe and North America. Restoring or diversifying habitats and reducing management pressures such as pesticides and grazing have been shown to positively affect wild pollinator populations and managed honey bee health ${ }^{13-15}$.
In response to evidence of declines, pollinators and pollination have attracted public and policy attention globally $y^{2,16}$ and substantial efforts are underway to respond, through national pollinator strategies and action plans ${ }^{17}$. The Intergovernmental Science-Policy Platform on Biodiversity and Ecosystem Services (IPBES) performed a global assessment of pollinators, pollination and food production from 2014 to $2016^{1}$. This underpinned the adoption of new commitments to support pollinator conservation by signatories to the Convention on Biological Diversity ${ }^{18}$ and subsequent steps towards developing national pollinator strategies and action plans in many nations ${ }^{17}$. One clear message from the pollination assessment was that evidence on the status and trends in pollinator populations, threats and the impacts of their decline, is concentrated in high-income countries, rather than regions thought to be most vulnerable to decreases in pollinator diversity $y^{19}$ and pollination services ${ }^{20}$. However, unlike the more recent IPBES global assessment on biodiversity and ecosystem services ${ }^{21}$, the pollination

\footnotetext{
'Department of Zoology, University of Cambridge, Cambridge, UK. ${ }^{2}$ School of Biological Sciences, University of East Anglia, Norwich, UK. ${ }^{3}$ Centre for Agri-Environmental Research, School of Agriculture, Policy and Development, Reading University, Reading, UK. ${ }^{4}$ PBES Secretariat, Bonn, Germany. ${ }^{5}$ nnstitute of Apicultural Research, Chinese Academy of Agricultural Sciences, Beijing, China. ${ }^{6}$ nnstituto de Investigaciones en Biodiversidad y Medioambiente (INIBIOMA), Universidad Nacional del Comahue-CONICET, Río Negro, Argentina. ${ }^{7}$ Department of Zoology, University of Calcutta, Kolkata, India. ${ }^{8}$ Center for Transdisciplinary and Sustainability Sciences, IPB University, Jalan Pajajaran, Indonesia. ${ }^{9}$ Department of Plant Protection, IPB University, Bogor, Indonesia. ${ }^{10} \mathrm{Facultad}$ de Ciencias Exactas, Físicas y Naturales, Universidad de Córdoba, Córdoba, Argentina. "Instituto Multidisciplinario de Biología Vegetal, CONICET-UNC, Córdoba, Argentina. ${ }^{12}$ Instituto de Investigaciones en Recursos Naturales, Agroecología y Desarrollo Rural, Universidad Nacional de Río Negro, Río Negro, Argentina. ${ }^{13}$ Instituto de Investigaciones en Recursos Naturales, Agroecología y Desarrollo Rural, Consejo Nacional de Investigaciones Científicas y Técnicas, Río Negro, Argentina. ${ }^{14}$ World Agroforestry Centre, Nairobi, Kenya. ${ }^{15}$ Prescott College, Prescott, AZ, USA. ${ }^{16}$ The New Zealand Institute for Plant \& Food Research Limited, Lincoln, New Zealand. ${ }^{17}$ Biosciences Institute, University of Sao Paulo, São Paulo, Brazil. ${ }^{18}$ Centre for Functional Biodiversity, School of Life Sciences, University of KwaZulu-Natal, Pietermaritzburg, South Africa. ${ }^{19}$ Institute of Ecology and Botany, Centre for Ecological Research, Vácrátót, Hungary. ${ }^{20}$ School of Applied Biosciences, Kyungpook National University, Daegu, Korea. ${ }^{21}$ International Centre of Insect Physiology and Ecology (icipe), Nairobi, Kenya. ${ }^{22}$ Naga Women's Union, Manipur, India. ${ }^{23}$ South African National Biodiversity Institute (SANBI), Kirstenbosch Research Centre, Claremont, South Africa. ${ }^{24}$ Department of Biological Sciences, FitzPatrick Institute, University of Cape Town, Rondebosch, South Africa. ${ }^{25}$ Agroécologie, AgroSup Dijon, INRAE, University of Bourgogne Franche-Comté, Dijon, France. 凶e-mail: lynn.dicks@zoo.cam.ac.uk
} 
Table 1 | Direct drivers of pollinator decline defined by the IPBES, including original wording shown in inverted commas, with section numbers indicated in brackets

\begin{tabular}{|c|c|}
\hline Short form & Definitions from IPBES pollination assessment ${ }^{1}$ \\
\hline Pollinator management & $\begin{array}{l}\text { Management, or husbandry, of bees (honey bees, bumblebees, stingless bees and solitary bees) for honey } \\
\text { production and of bees or other insects for pollination. 'Two major Apis species are managed around the world: } \\
\text { the western honey bee Apis mellifera and the eastern honey bee Apis cerana' (Section 2.4.2.1). 'Five species of } \\
\text { bumblebees are currently used for crop pollination, the major ones being Bombus terrestris from Europe and Bombus } \\
\text { impatiens from North America' (Section 2.4.2.2). 'Bee management is a global and complex driver of pollinator loss' } \\
\text { (Section 2.4.3). }\end{array}$ \\
\hline Pests and pathogens & $\begin{array}{l}\text { Parasites, pathogens and disease of all pollinating animals are included, both naturally circulating in populations and } \\
\text { those associated with human management. 'Bee diseases by definition have some negative impacts at the individual } \\
\text { bee, colony or population level. Parasites and pathogens can be widespread in nature but may only become } \\
\text { problematic when bees are domesticated and crowded' (Section } 2.4 .1 \text { ). }\end{array}$ \\
\hline Pesticide use & $\begin{array}{l}\text { 'Pesticides (fungicides, herbicides, insecticides, acaricides, etc.) are primarily used in crop and plant protection } \\
\text { against a range of pests and diseases and include synthetic chemicals, biologicals, for example, Bacillus thuringiensis } \\
\text { (Bt) or other chemicals of biological origin such as spider venom peptides' (Section 2.3.1). Veterinary medicines } \\
\text { are also included. }\end{array}$ \\
\hline Land management & $\begin{array}{l}\text { '[A]rrangements activities and inputs people undertake in a certain land cover type ...' (Section 2.2.1). This includes } \\
\text { mowing, cultivating, grazing, burning and cropping regimes and non-pesticide inputs, particularly fertilizers. } \\
\text { Pesticides were considered separately, as there are large amounts of evidence specific to them. }\end{array}$ \\
\hline Land cover and configuration & $\begin{array}{l}\text { 'Land cover has been defined by the UN FAO as the observed (bio)physical cover on the earth's surface' } \\
\text { (Section 2.2.1). This includes the extent of different habitat and land use types and their spatial configuration at } \\
\text { landscape scale. }\end{array}$ \\
\hline Invasive alien species & $\begin{array}{l}\text { 'Alien species are defined as a (non-native, non-indigenous, foreign, exotic) species, subspecies or lower taxon } \\
\text { occurring outside of its natural range (past or present) and dispersal potential (that is outside the range it occupies } \\
\text { naturally or could occupy without direct or indirect introduction or care by humans) and includes any part, gametes } \\
\text { or propagule of such species that might survive and subsequently reproduce. 'Alien invasive species' are alien } \\
\text { species that become established in natural or seminatural ecosystems and are an agent of change, threatening native } \\
\text { biological diversity' (Section 2.5.1). }\end{array}$ \\
\hline GMOs & $\begin{array}{l}\text { 'Genetically modified (GM) organisms (GMOs) are organisms that have been modified in a way that does not occur } \\
\text { naturally by mating and/or natural recombination. One of the most common methods to do this is by bioengineering } \\
\text { transgene(s) into the new organism. The most common plant transgenes confer herbicide tolerance (HT) or toxicity } \\
\text { towards herbivores (insect resistance, IR), although other characteristics have been also engineered (for example, } \\
\text { drought resistance in wheat, nutritional values in sorghum)' (Section 2.3.2). }\end{array}$ \\
\hline Climate change & $\begin{array}{l}\text { '[A] change in the state of the climate that can be identified ... by changes in the mean and/or the variability of its } \\
\text { properties, and that persists for an extended period, typically decades or longer' (Section } 2.6 \text { ). }\end{array}$ \\
\hline
\end{tabular}

assessment did not directly compare and rank the relative importance of major drivers of pollinator decline or make any integrated assessment of the risks it generates for society, either at global or at regional levels. Consequently, although researchers have made broad, global recommendations about how to respond to pollinator decline ${ }^{16}$, addressing specific drivers and risks at national or regional scales appropriate for policy implementation has been more challenging 22 .

Here, we used a structured expert elicitation technique and a globally representative group of 20 pollinator and pollination experts, all authors of this paper, to evaluate the relative importance of eight major direct drivers (or causes) of observed pollinator decline and the risks to human well-being associated with ten direct impacts of pollinator decline defined by the IPBES report ${ }^{1}$ (Tables 1 and 2 and Supplementary Table 1). We separately assessed each of six global continental regions, with the exceptions that, for biogeographic and geopolitical reasons, the Pacific islands were grouped with Asia (Asia Pacific) and not with Australia and New Zealand, while MesoAmerica and the Caribbean were grouped with South America into Latin America (Methods and Extended Data Fig.1). We did not assess indirect impacts, such as increased land conversion in response to lower crop yields. Nor did we consider interactions between multiple drivers, despite their likely influence on pollinator decline ${ }^{2}$, because knowledge about driver interactions remains largely incomplete and insufficient for the scale and scope of analysis here.
Understanding and communicating risks to human well-being associated with biodiversity loss play a central role in raising awareness of our dependence on nature and in driving the transformative societal change required to conserve and restore biodiversity worldwide $^{23}$. We take a scientific-technical approach, in which a risk is understood as the probability of a specific hazard or impact taking place. We used a semiquantitative risk matrix, with risk scores calculated as the product of probability, scale and severity of impacts and a 'four-box model' established by the IPBES (Fig. 1 and Table 3) to communicate levels of confidence ${ }^{1}$, thus highlighting the key known 'unknowns' in current scientific understanding. Our assessment used a modified Delphi technique ${ }^{24}$, an approach designed to reduce bias but particularly suitable for elicitation of expert judgements about complex issues, where the judgement requires a range of different perspectives and areas of expertise not necessarily held by each participant ${ }^{24}$.

\section{Results}

What is driving pollinator declines? Figure 2 shows final scores for the importance of the six drivers defined in Table 1, following three rounds of scoring. Globally, land cover and configuration and land management were the most important drivers of pollinator declines (Fig. 2 and Supplementary Tables 2 and 4). Land cover and configuration was scored 'very important' in all six regions, while land management was the only variable considered to be 'the most important' in any region (Europe) and was 'very important' in all 
Table 2 | Direct impacts of pollinator decline on human well-being defined by IPBES', including original wording from Table 6.2.1 of ref. ${ }^{1}$ shown in inverted commas

\begin{tabular}{|c|c|c|}
\hline Impact & Definition & Example \\
\hline \multicolumn{3}{|c|}{ Impacts on food production } \\
\hline Pollination deficits & $\begin{array}{l}\text { 'Crop pollination deficit leading to lower } \\
\text { quantity or visual/nutritional quality of food } \\
\text { (and other products...)'. }\end{array}$ & $\begin{array}{l}\text { Reduction in the quantity or quality of food, fibre, fuel or seed that can } \\
\text { be produced, as a result of pollinator loss. }\end{array}$ \\
\hline Yield instability & $\begin{array}{l}\text { 'Crop yield instability due to loss of pollinators } \\
\text { or change in pollinator communities'. }\end{array}$ & $\begin{array}{l}\text { Crop yields becoming less stable or predictable between years or } \\
\text { locations. }\end{array}$ \\
\hline Honey production & $\begin{array}{l}\text { 'Fall in honey production (and other hive } \\
\text { products)'. }\end{array}$ & $\begin{array}{l}\text { Reduction in the amount of honey or hive products that can be } \\
\text { produced, as a result of pollinator loss. }\end{array}$ \\
\hline Food system resilience & $\begin{array}{l}\text { 'Decline in long-term resilience of food } \\
\text { production systems'. }\end{array}$ & $\begin{array}{l}\text { Resilience is the ability of the food production system to withstand or } \\
\text { recover from shocks or adverse effects, such as changes in climate. }\end{array}$ \\
\hline Wild fruit availability & $\begin{array}{l}\text { 'Decline in yields of wild fruit, harvested from } \\
\text { natural habitats by local communities'. }\end{array}$ & $\begin{array}{l}\text { Fruits or seeds harvested for food by people (not by animals). Could } \\
\text { include, for example, blueberry harvesting from wetlands or Rubus } \\
\text { fruticosus fruits harvested from hedgerows. }\end{array}$ \\
\hline Managed pollinators & 'Reduced availability of managed pollinators'. & $\begin{array}{l}\text { Managed pollinators are animals used to provide crop pollination, } \\
\text { rather than for the production of honey. }\end{array}$ \\
\hline \multicolumn{3}{|c|}{ Impacts on biocultural diversity } \\
\hline Wild pollinator diversity & $\begin{array}{l}\text { 'Loss of wild pollinator diversity' leading to } \\
\text { long-term changes in network/food web } \\
\text { interactions. }\end{array}$ & $\begin{array}{l}\text { Loss of species richness or abundance of particular species of wild } \\
\text { pollinators, including invertebrates and vertebrates. This impact is } \\
\text { intermediate; ultimate impacts on human well-being can include food } \\
\text { system resilience, aesthetic value, cultural practices and traditions. }\end{array}$ \\
\hline Wild plant diversity & $\begin{array}{l}\text { 'Loss of wild plant diversity due to pollination } \\
\text { deficit'. }\end{array}$ & $\begin{array}{l}\text { Loss of species richness or abundance of particular species of } \\
\text { wild plants due to pollination deficit. This impact is intermediate; } \\
\text { ultimate impacts on human well-being can include loss of ecosystem } \\
\text { services such as erosion prevention, aesthetic value, cultural practices } \\
\text { and traditions. }\end{array}$ \\
\hline Aesthetic values & $\begin{array}{l}\text { 'Loss of aesthetic value, happiness or } \\
\text { well-being associated with wild pollinators or } \\
\text { wild plants dependent on pollinators'. }\end{array}$ & $\begin{array}{l}\text { This could include amenity values of specific plant communities, } \\
\text { values of emblems or symbols and the value of pollinators as sources } \\
\text { of inspiration for art, music, literature, religion and technology. }\end{array}$ \\
\hline Cultural values & $\begin{array}{l}\text { 'Loss of distinctive ways of life, cultural } \\
\text { practices and traditions in which pollinators or } \\
\text { their products play an integral part'. }\end{array}$ & $\begin{array}{l}\text { Cultures, traditions and behaviours involving pollinators or pollinator } \\
\text { products. This includes beekeeping, honey-hunting and specific } \\
\text { dances or rituals associated with pollinators. }\end{array}$ \\
\hline
\end{tabular}

other regions except Africa (Fig. 2). These conclusions are supported by considerable evidence from multiple regions ${ }^{25-27}$ and continuing global trends towards agricultural expansion, conventional intensification and urbanization in regions of the Global South, driven by international trade ${ }^{28}$. Land management was considered less important in Africa, where access to the necessary financial and technical capital to intensify production is still limited ${ }^{29}$ and where there was considerable uncertainty (categorized as 'inconclusive') over the influence of land cover and configuration (Fig. 2).

Pesticides were scored as 'important' or 'very important' drivers of pollinator decline in all regions, with the greatest confidence in Latin America and Asia Pacific (Fig. 2). Pesticides were considered less important than land management in Europe and Australia/New Zealand but much more important in Africa (Fig. 2). The adverse effects of pesticides on pollinators have received considerable attention in recent years, following studies demonstrating widespread exposure $^{30}$ and detrimental effects on populations $s^{31,32}$ or diversity ${ }^{27}$. There is far less evidence available to quantify the exposure in regions beyond Europe and North America. Also, despite very rapid increases in pesticide use since 1990 in middle-income countries of Africa, Latin America and Asia Pacific ${ }^{33}$, pesticide regulations are weaker in the Global South, adding considerably to the risk ${ }^{1,33,34}$.

Climate change was considered an 'important' or 'very important' driver in every region. There was, however, unanimous lack of confidence over its importance relative to other drivers. In every region, except Africa, median confidence scores were 'medium' and, in Africa, seven of the ten scorers responded that climate change effects are 'unknown' (Extended Data Fig. 2 and Supplementary Table 2). Long-term data scarcity limit and confound the demonstration of current climate change effects on pollinators and available studies are restricted to few taxa such as bumblebees ${ }^{11}$ and butterflies ${ }^{35}$.

Genetically modified organisms (GMOs) were considered the least important driver overall, except in Latin America (Fig. 2), which is the second largest producer of GM crops among our regions, after North America ${ }^{36}$. Emerging evidence of potential impacts of herbicide-tolerant crops and associated glyphosate use on honey bees was discussed in the Latin American context (see Supplementary Table 10, now reviewed ${ }^{37}$ ). Levels of confidence and agreement tended to be low for GMOs and invasive alien species as drivers of pollinator decline, due to very limited available evidence. In the case of GMOs, impacts on pollinators vary according to the type of GM crop ${ }^{2}$ and are difficult to separate from the effects of land cover and configuration because such crops are often produced in large monocultures.

What are the risks to human well-being? Figure 3 shows the final risk scores following three rounds of scoring, partitioned into probability and magnitude (scale $\times$ severity), for each of the direct impacts listed in Table 2, in each major global region. Overall, loss of wild pollinator diversity and crop pollination deficits were 


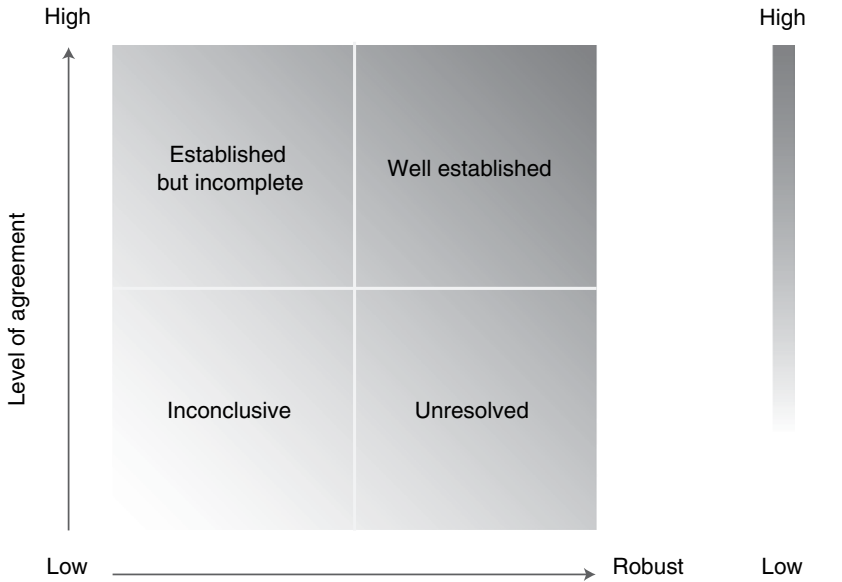

Quantity and quality of evidence

Fig. 1 | The four-box model for the qualitative communication of confidence. Confidence increases towards the top-right corner as suggested by the increasing strength of shading?

the highest and most widespread risks, scoring as serious or high risks in every region (Fig. 3 and Supplementary Tables 3 and 7). Although much of the published evidence for pollinator declines is from Europe and North America (where the evidence was considered 'well established') ${ }^{2}$, there is growing evidence of pollinator declines in other regions ${ }^{19,38}$, including vertebrate pollinators $^{39}$, along with global evidence of general biodiversity decline ${ }^{23}$. Evidence for crop pollination deficits is also growing across several regions ${ }^{6,40-42}$ (Fig. 3), although for Australia/New Zealand and Africa, the degree of confidence was 'inconclusive', indicating low amounts of evidence and low agreement among our experts (Table 3 gives definitions). This is a particular concern in Africa and Asia Pacific, where pollinated crops are of notable nutritional ${ }^{3}$ and economic ${ }^{43}$ value to livelihoods and well-being. Yield instability in pollinator-dependent crops, which is higher than that for non-dependent crops at global scale ${ }^{44}$, was classed as a serious or high risk in four of the six regions but moderate in Europe and North America, where highly pollinator-dependent crops tend to be less widely grown and less important to total agricultural output. Direct impacts of wild fruit production losses had very low risk scores in economically developed regions of North America, Europe and Australia/New Zealand (median scores <6) but were classed as a serious risk in Africa, Asia Pacific and Latin America (Fig. 3). These regions are dominated by low- to middle-income countries where, at least for Africa and Asia Pacific, large portions of the population live in rural communities ${ }^{45}$.

Risks were greatest in Latin America compared to other regions (Supplementary Table 3: mean risk score across all ten impacts $=48.2$ ), with four 'high' risks (pollination deficits, yield instability, food system resilience and wild pollinator diversity) and five 'serious' risks (all others except managed pollinators). This reflects the high diversity of insect-pollinated crops grown and exported throughout the region, often by smallholder farmers in and around areas of natural habitats that contain a high diversity of pollinating insects ${ }^{46}$. Continuing losses of pollinators are therefore likely to destabilize both regional food production and international trade, affecting livelihoods across the region. Like other regions of the Global South, Latin America is also home to a high diversity of extant indigenous cultures and people, many of whom rely on subsistence agriculture and natural resources such as non-timber forest products $^{47}$, increasing the risks from a decline in honey, wild fruits and cultural values.

\begin{tabular}{|c|c|c|}
\hline $\begin{array}{l}\text { Confidence } \\
\text { category }\end{array}$ & Definition & $\begin{array}{l}\text { Thresholds, based on third } \\
\text { round modified Delphi scores }\end{array}$ \\
\hline \multirow[t]{2}{*}{ Well established } & Robust evidence & $\begin{array}{l}\text { Confidence score } \geq 66.7 \% \text { and } \\
\text { proportion unknowns }<40 \%\end{array}$ \\
\hline & High agreement & $\begin{array}{l}\text { For risks, } \sum \mathrm{IQRs} \leq 3 \text {; for drivers, } \\
\mathrm{IQR} \leq 1\end{array}$ \\
\hline \multirow[t]{2}{*}{$\begin{array}{l}\text { Established but } \\
\text { incomplete }\end{array}$} & $\begin{array}{l}\text { Low-quality } \\
\text { evidence }\end{array}$ & $\begin{array}{l}\text { Confidence score }<66.7 \% \text { or } \\
\geq 40 \% \text { of responses 'unknown' }\end{array}$ \\
\hline & High agreement & $\begin{array}{l}\text { For risks, } \sum \mathrm{IQRs} \leq 3 \text {; for drivers, } \\
\mathrm{IQR} \leq 1\end{array}$ \\
\hline \multirow[t]{2}{*}{ Unresolved } & Robust evidence & $\begin{array}{l}\text { Confidence score } \geq 66.7 \% \text { and } \\
\text { proportion unknowns }<40 \%\end{array}$ \\
\hline & Low agreement & $\begin{array}{l}\text { For risks, } \sum \mathrm{IQRs}>3 \text {; for drivers, } \\
\mathrm{IQR}>1\end{array}$ \\
\hline \multirow[t]{2}{*}{ Inconclusive } & $\begin{array}{l}\text { Low-quality } \\
\text { evidence }\end{array}$ & $\begin{array}{l}\text { Confidence score }<66.7 \% \text { or } \\
\geq 40 \% \text { of responses 'unknown' }\end{array}$ \\
\hline & Low agreement & $\begin{array}{l}\text { For risks, } \sum \mathrm{IQRs}>3 \text {; for drivers, } \\
\mathrm{IQR}>1\end{array}$ \\
\hline
\end{tabular}

We follow the four-box model for the qualitative communication of confidence (Fig. 1). The degree of confidence in each finding is based on the quantity and quality of evidence, represented by confidence scores (Methods) and level of agreement among scorers, represented by interquartile ranges (IQRs) of expert scores for each variable.

In contrast to Latin America, Africa had very low risk scores for honey production and managed pollinators (both 'low' risk; Fig. 3 and Supplementary Table 3). Beekeeping is unique in Africa since it is the only global region that has large, genetically diverse populations of native honey bees (Apis mellifera, various subspecies) still thriving in the wild ${ }^{48}$. In fact, numbers of managed hives are increasing in many African countries due to limited colony losses and managed honey bee populations relatively resilient to Varroa mite ${ }^{49}$.

The risk of loss of aesthetic values, happiness or well-being associated with wild pollinators or wild plants dependent on pollinators was perhaps the most difficult to score in all regions. In some contexts, one can make an argument that aesthetic values associated with pollinators are increasing, as people become more aware of their roles, beauty and diversity. Discussions focused on what constitutes aesthetic values and how they might be changing in response to pollinator decline (Supplementary Table 11). This risk varied regionally, with Latin America and Africa scored highest (42) and lowest (4) risk, respectively (Fig. 3 and Supplementary Table 3). While clear links exist between people and pollinators or pollinator-dependent plants in both regions, for Latin America, these links are often related to specific threatened taxa, such as hummingbirds and orchids. In Africa, connections with pollinator-dependent plants are frequently associated with entire landscapes, such as the flower-rich shrubland of Namaqualand, southern Africa, making potential impacts of pollinator decline on aesthetic values less clear (Supplementary Table 11).

Europe was the region where human well-being was considered at the lowest risk from pollinator declines overall (mean risk score $=19.6$ ), with no 'high' risks and only two 'serious' risks (pollination deficits and wild pollinator diversity). Unlike Latin America, many European countries grow relatively few crops that are highly pollinator dependent and food systems, particularly within the European Union, are highly industrialized and globalized, greatly reducing the importance of wild fruits and buffering against the impacts of global change on food system resilience (both 'low' risk). Despite evidence that habitats containing pollinator-dependent plants are aesthetically valued in Europe $e^{50}$, their cultural importance may be lower than elsewhere in the world, although this was 


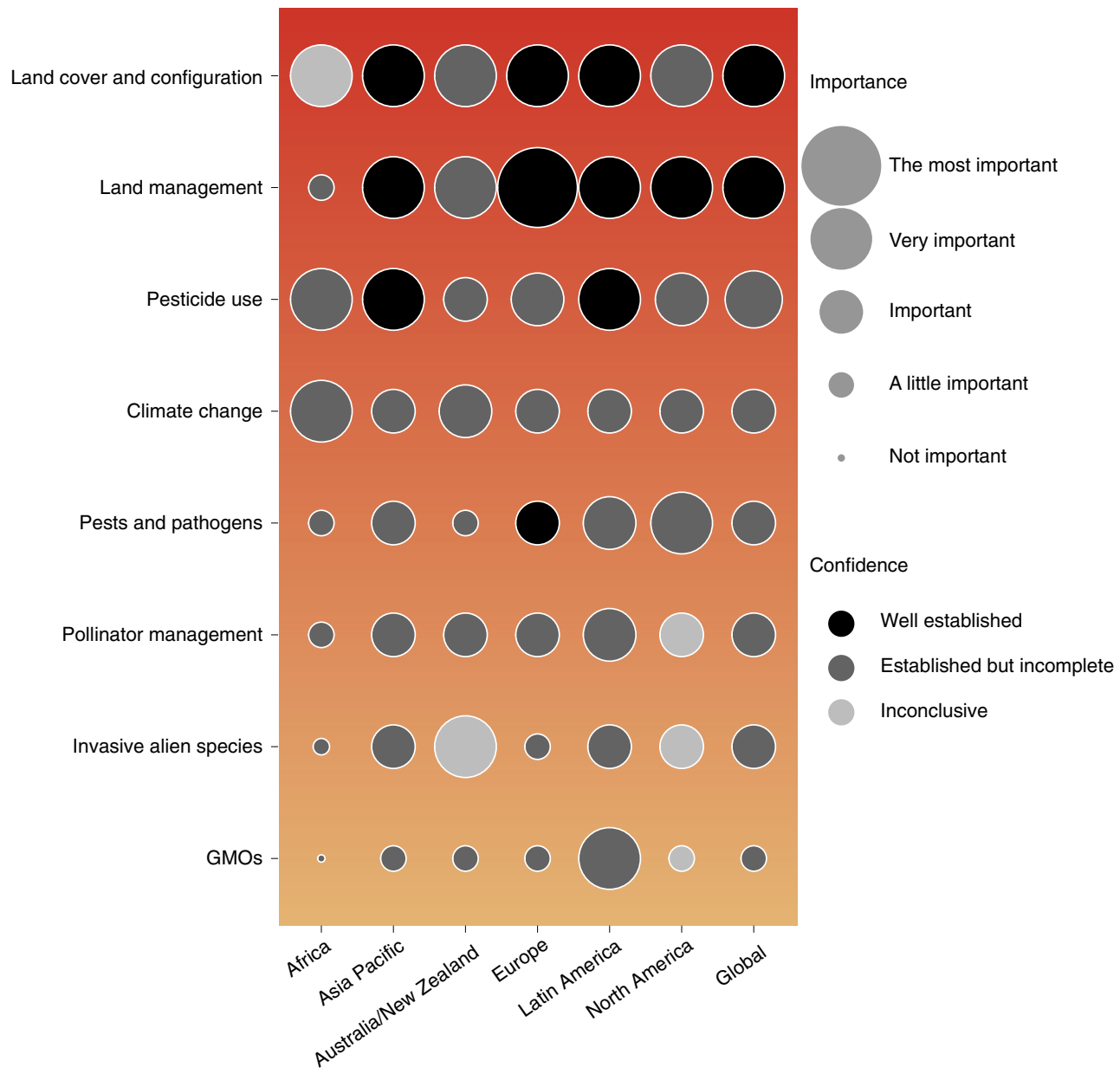

Fig. 2 | Assessment of the importance of eight major drivers of pollinator decline, for six regions and a global median (right). Importance is represented by circle size, reflecting median scores ranging from 1 ('not important) to 5 ('the most important') across nine or ten experts, following three rounds of anonymous scoring (Supplementary Table 2). Drivers are ordered according to effects on score values estimated by proportional odds models (Supplementary Table 4), with higher scoring drivers at the top. All drivers except 'pests and pathogens' were scored significantly differently from 'climate change', either higher or lower. Degree of confidence is shown by the grey-scale, following the IPBES four-box model based on the confidence score and level of agreement, according to the criteria in Table 3. No driver was assigned a confidence category of 'unresolved'. Background shading gradient from yellow to red indicates increasing importance of drivers as a cause of pollinator decline.

highly uncertain, with our risk score for 'cultural values' in Europe categorized as 'inconclusive' due to low confidence and low agreement among scorers.

Loss of access to managed pollinators was only considered a serious risk to people in North America, where honey bees A. mellifera represent a key input to large-scale, industrialized cropping systems such as almond ${ }^{51}$ and have suffered serious declines in the past due to outbreaks of disease, pests and 'colony collapse disorder'52. The probability of the same occurring in, say, Latin America or Asia Pacific, was considered far lower, even if the severity of the impact would be similar (Fig. 3 and Supplementary Table 3). Experts were divided (low agreement) on the risk from losing managed pollinators in Europe (Fig. 3), where markets for pollination services are less well developed than in North America ${ }^{53}$, and in Latin America, where the number of managed honey bee colonies has expanded substantially but pressures on their populations remain high?

Across both risks and drivers, there was high agreement but low confidence for most factors, placing them in the 'established but incomplete' confidence category. Our confidence in several direct impacts was low because of numerous gaps in knowledge about the ecology and status of all but the most common pollinator species and the relationships between pollinators, human economies and culture ${ }^{20,54}$. Furthermore, while statistical information on crop production, managed pollinators and honey production is often collected at a national scale, the quality of these data varies considerably within a region and over time and does not capture subsistence agriculture, particularly in the Global South.

\section{Discussion}

In our analysis, the global ranking of drivers of pollinator decline by importance (Fig. 2) differs from the order of relative impact of direct causes of biodiversity loss (or 'changes in the fabric of life') presented by Díaz et al. on the basis of the IPBES global assessment $^{23}$. In both cases, land use change (here, land cover and configuration) for terrestrial realms is the most important driver but, for the whole of nature ${ }^{23}$, 'direct exploitation' is the next most important driver, followed by climate change, pollution and invasive alien species. For pollinators, direct exploitation is broadly equivalent to 'pollinator management' (not including direct harvesting of pollinators or pollinator products, which is not suggested as a major driver of pollinator decline). This was ranked with lower importance than climate change, pesticides and pests and pathogens in our assessment. For pollinators, climate change was ranked below pesticides as a driver, perhaps reflecting more complete evidence that current 

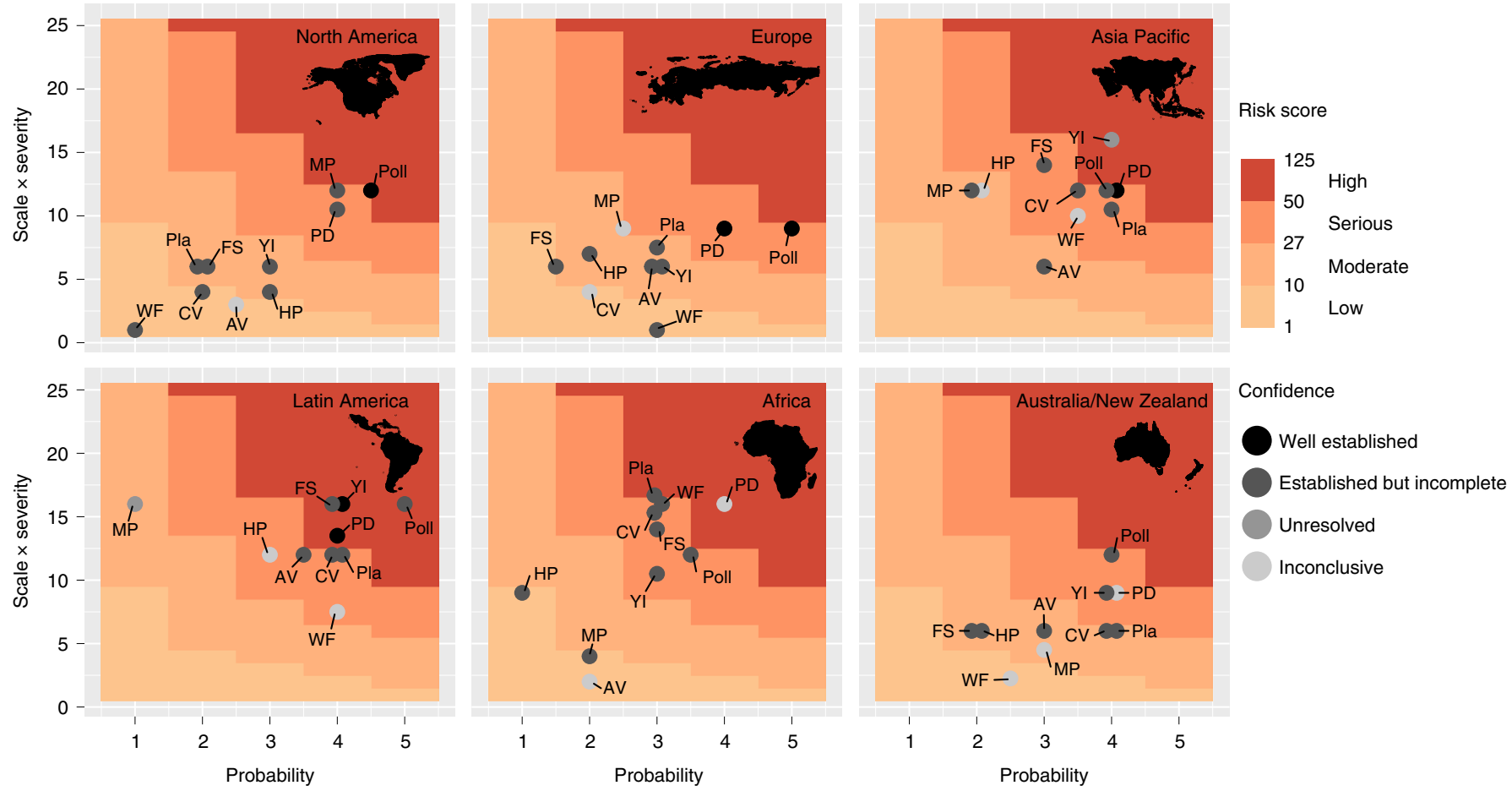

Fig. 3 | Assessment of the risks to human well-being associated with pollinator decline. Ten direct impacts are assessed separately, with risks evaluated on the basis of probability, scale and severity of specific impacts occurring in six global regions. PD, pollination deficits; $Y$, yield instability; HP, honey production; FS, food system resilience; WF, wild fruit availability; Pla, wild plant diversity; Poll, wild pollinator diversity; MP, managed pollinators; AV, aesthetic values; CV, cultural values. Scores are median scores across five to ten experts, following three rounds of anonymous scoring (Supplementary Table 3). The underlying risk matrix, shown by the background colours, provides categories of risk according to an overall risk score (the product of probability, scale and severity scores): $<10=$ low risk; $10-<28=$ moderate risk; $28-50$ serious risk; $>50=$ high risk. Degree of confidence is shown by the grey-scale, following the IPBES four-box model based on the confidence score and level of agreement, according to the criteria in Table 3. Impacts with the same scores on both axes are shown overlapping, jittered evenly, to enable confidence category to be visible.

pesticide use negatively impacts pollinator populations ${ }^{12,31}$, through a range of lethal and sublethal effects. Climate change impacts on pollinators are likely to be longer term. Much of the current evidence shows shifting ranges, which only sometimes translate into population declines ${ }^{11}$ or highly uncertain projected future distributions under climate change. Although these two analyses used different methods for ranking drivers (Díaz et al. ${ }^{23}$ quantified the relative impact of each driver on the basis of rankings in published studies comparing two or more drivers), it is not surprising that the relative importance of drivers differs, when focusing on a functionally defined subset of organisms (pollinators) that are almost all relatively small in size.

Despite high-profile, extensive research on the drivers and impacts of pollinator decline, our analysis reveals considerable scientific uncertainty about what this means for human society, regionally and globally. There are clear risks of wild pollinator diversity loss and crop pollination deficits globally, yet less is understood about the broader implications for human well-being. The case for action to address pollinator decline is most clearly made for Latin America (Fig. 3).

We followed an explicit, transparent and systematic process of risk assessment, as recommended by Zommers et al. ${ }^{55}$ for robust climate change risk assessment. Even so, a number of limitations to this approach have been clearly defined ${ }^{56,57}$. Perhaps the most pertinent here is the potential for our results to be influenced by the value judgements and world views of our individual experts. For example, when rating 'severity' of impacts, people whose lives are directly affected might be inclined to rate severity more highly than those unaffected. When rating 'probability', interpretation of verbal scales by individual experts can be poorly aligned or even overlap, when measured against numerical scales; in extreme cases, what is 'likely' to one person can be considered 'unlikely' by another ${ }^{58}$. One way to reduce this subjectivity would be to define explicit, sharp or fuzzy boundaries for the categories in our verbally described scales (Supplementary Table 1), using specified numerical scales, thereby reducing 'vagueness ${ }^{59}$. Several underlying numerical scales can be conceptualized for all the elements of risk we assessed. Possible scales could be derived from available data on the impacts themselves over time or space (for probability), the numbers or proportions of people who could be affected (for scale) and contributions to health, well-being and income from particular activities (for severity). For example, to judge the probability of a fall in honey production, we discussed the relevance and quality of available data on honey production and numbers of managed honey bee hives ${ }^{60}$, and the trends shown by these datasets, for each region. To judge the scale of impact of a fall in honey production in terms of numbers of people affected, we considered numbers of beekeepers, honey hunters and honey consumers, across each region. To judge the severity of this impact, we considered the proportions of beekeepers', farmers' and honey hunters' incomes that come from honey, and the relative impacts of honey on people's individual health outcomes (Supplementary Table 11). However, for most of our impacts, numerical data were available only for a small proportion of the issues considered, in a subset of possible contexts and usually not at regional scale, so using numerically specified boundaries would still have demanded subjective judgements or speculation. In these circumstances, providing numerical scales to delineate the categories would represent an unfounded and misleading level of precision. 
Our process reveals several major knowledge gaps. There is an urgent need for research in Africa ${ }^{61}$, to address the substantial uncertainties around the risks to people from pollination deficits (Fig. 3), and the importance of changes in land cover and configuration, as a driver of pollinator decline (Fig. 2). In more developed regions, especially North America, we lack understanding of the scale and severity of impacts of pollinator decline on human well-being (Supplementary Table 3). Globally, the consequences of climate change for pollinators and pollination remain poorly understood but its impacts will clearly increase in prominence in the coming decades $^{23}$. As climate change is very likely to interact with other drivers of pollinator decline, a focus on how to mitigate and adapt to it should be central to pollinator research and conservation strategies.

\section{Methods}

We assessed drivers and risks using a modified version of a formal consensus method known as the Delphi technique ${ }^{24}$, in which the second and third rounds of anonymous, independent scoring took place following detailed discussions at a face-to-face workshop in November 2017. This modification of the Delphi technique is frequently used in environmental research, where issues are multidisciplinary and interpretations of the same phrase can differ strongly among individuals ${ }^{62}$. All but one of the authors of this paper (referred to here as 'experts') took part in all rounds of the Delphi process (D.S. facilitated only and did not score). This set of 20 pollination experts was carefully selected to cover the range of necessary expertise, including biodiversity science, economics, social science and indigenous and local knowledge, and to ensure that the main global regions were each represented by at least two scorers either originating from or mainly working in that region. Thirteen of the 21 authors (62\%) were also authors of the IPBES global pollination assessment ${ }^{1}$, mostly nominated by their respective national governments, and the team had a balanced gender ratio of 11 men to ten women.

Definitions of regions, parameters and scores. We divided the world into six global regions, largely representing geographic continents of North America, South America, Asia, Europe, Africa and Oceania, with two key differences: (1) we included the Pacific islands in a region known as 'Asia Pacific', rather than combining them with Australia and New Zealand in the geographic continent 'Oceania'. Our Asia Pacific region is equivalent to most of the Asia Pacific as defined by IPBES but excludes Australia and New Zealand. We named 'Australia/New Zealand' as a separate region because they are very different from mainland Asia and the Pacific islands both biogeographically and geopolitically (Supplementary Fig. 1); (2) we included the countries of Central America and the Caribbean with Latin America, rather than with North America as they would be in the geographic continent. Our 'Latin America' region includes the subregions of Mesoamerica, the Caribbean and South America, as defined by IPBES (Supplementary Fig. 1)

For each region, experts individually assigned probability, scale and severity scores for each of ten impacts of pollinator decline and importance scores to each of eight drivers of pollinator declines defined by the IPBES ${ }^{1}$ (Tables 2 and 1, respectively), using the five-point Likert scales described in Supplementary Table 1. All scores were accompanied by a confidence score of low, medium or high, enabling experts to qualify their judgements with a level of confidence, on the basis of the amount of evidence they were aware of and its quality.

The following definitions of probability, scale and severity were available for authors to consult throughout the process:

- Probability. A high probability of impact suggests that the impact is already taking place or is very likely, at least in some circumstances. Low probability implies that the impact is not taking place or is unlikely. Unknown means there is not enough evidence to make a judgement on whether or not the impact is happening or likely to happen.

- Scale of impact either refers to the numbers of people or to the area affected. Large means there is evidence for impacts on people and livelihoods, either over a large area or affecting many people. Moderate means there is evidence for impacts on people and livelihoods, either over a moderate area or affecting a moderate proportion of people. Small means there is evidence for impacts on people and livelihoods, either in a small, localized area or only affecting a small number of people. Unknown means there is not enough evidence on the scale of this impact to make a judgement.

- Severity of impact refers to the nature of the impact on individual people or families. Large means there is evidence for a substantial or severe impact on people and livelihoods. Moderate means there is evidence for a moderate impact on people and livelihoods and small means a small impact. Unknown means there is not enough evidence on the severity of this impact to make a judgement.

Experts rated the importance of each driver in affecting pollinators, at the present time, in each specific region, on a 1-5 scale from 'not important' to 'the most important' (Table 1 and Supplementary Table 1).
We set an a priori expectation of consensus as an interquartile range of $<2$ between scores for a particular element (not including confidence). This still allowed us to distinguish between high and low agreement following criteria in Table 3, in which high agreement is denoted by mean IQR $\leq 1$ (where half of all scores are the same or an adjacent score) (Table 3).

Three iterative rounds of scoring. In an initial scoping phase, all experts were invited to comment on the proposed scoring structure described above. Following this, the first round of scoring was conducted online in October 2017. Each expert was asked to score for all regions, considering the evidence in the IPBES report ${ }^{1}$ alongside their own expertise. Experts could add comments to support their scores and were encouraged to cite parts of the IPBES report ${ }^{1}$ and other specific literature. Scores and comments were compiled anonymously and summaries sent to all experts, detailing the median and interquartile range of scores for each element and the proportions of 'unknown' responses.

Each expert was then assigned a region (always one they were familiar with) and a driver and asked to play a cynic role, doing focused background research to challenge, refute or support the scores from the first round, with evidence. Cynic roles were not made known during later discussions but cynics were invited to comment appropriately and to actively introduce new evidence to the discussions.

In November 2017, all experts attended a 3-day, face-to-face workshop in Reading, UK. Experts were divided into two groups, which each discussed the results from the first round, and the evidence that supports them, for three regions. Group 1 discussed and scored in rounds 2 and 3 for Europe, North America and Africa; group 2 discussed and scored Latin America, Asia Pacific and Australia/New Zealand. Discussions were facilitated and notes taken throughout. Facilitators kept in contact and discussed any specific issues arising about how to score, to ensure that both groups responded in the same way. At the end of each part of the discussion, participants scored again for each element of risk and each driver, for each region in turn. Scoring was conducted independently and anonymously, using Excel spreadsheets on personal laptops. All members of a group were encouraged to score for each region discussed in their group, with the following guidance: 'Score if you can (but you don't have to). If you feel confident to score for a region outside your own personal knowledge, please do so. These issues are complex and open to interpretation. This is why we employ a subjective scoring process, with anonymous scoring. Listen to the discussion, and then score as you understand it'.

These round 2 results were compiled as before and any scores with IQR $\geq 2$ (our a priori criterion for consensus), progressed to round 3 for rescoring.

Round 3 scoring took placed on the third day of the workshop in a plenary discussion. This allowed a further opportunity for any consistent differences in scoring or approach across groups to be revealed but none was evident. Second round scores were presented and made the subject of debate and discussion. Experts scored again anonymously and independently, using laptops, for the regions they scored for in round 2, although the discussion was open to both groups. In total, 19 variables (three drivers and 16 impacts) were rescored, along with associated confidence levels. Due to an error, four impact variables (Latin America: pollination deficit (severity), yield instability (scale), wild fruit availability (scale) and wild plant diversity (scale)) with IQR $\geq 2$ were not flagged for rescoring during the workshop and were later rescored during a teleconference. Only five of the ten scorers from group 2 were able to attend the teleconference, due to time differences, so these four variables have only $n=5$ scorers in the final dataset (Supplementary Fig. 3). All other variables have at least eight scorers. Following the third round, three variables still failed to reach consensus (IQRs $\geq 2$ ) - Australia/New Zealand: pollination deficit (probability), wild fruit availability (probability) and Latin America: managed pollinators (probability) (Supplementary Table 3).

Analysis. Median scores following the third round of scoring were used to derive risk scores (the product of probability, scale and severity scores) and associated risk categories (boundaries visualized in Fig. 3), importance scores for drivers and confidence categories for all final scores, following criteria given in Table 3. In assigning confidence categories, the quantity and quality of evidence was based on assigned confidence scores for each risk or driver. The confidence score is the percentage of the maximum possible confidence score ( 9 for risks, 3 for drivers), represented by the median confidence scores from the final round, with the three medians summed in the case of impacts (confidence score for risk $=\left(\sum\right.$ confidence scores for probability, scale and severity $/ 9) \times 100)$ ).

Overall global scores for the importance of drivers were calculated as a median of the six region-level scores and confidence scores, to ensure equal weight was given to each region (although the numbers were unchanged if individual scores across all six regions were used). We did not calculate overall global risk scores for different impacts of pollinator decline because these scores were based on assessments of probability, scale and severity for different global regions and it does not make sense to average these across regions. All figures were drawn using the ggplot2 package $\mathrm{e}^{63}$ in $\mathrm{R}$ v.4.0.0.

We proposed that the scores participants gave for each component of the risk or driver importance were dependent on the impact or driver being scored and on 
the region being scored, rather than reflecting individual scorer differences. We tested this hypothesis using cumulative link models and cumulative link mixed models with logit link functions (also called proportional odds or ordinal logistic regression models), with the ordinal package ${ }^{64}$ in $\mathrm{R}$ v.4.0.3. The top and bottom two score categories (scores 1 and 2 and 4 and 5, respectively) were collapsed to create three-point scales for probability, scale and severity of impacts and importance of drivers.

We considered the effect of region and impact, or region and driver, on score for each of four dependent variables: probability, scale, severity and importance. 'Unknown' responses were treated as missing values for this analysis. The dataset was not large enough to examine the interaction between region and impact or driver with this type of model ( $n \leq 10$ scorers for each combination of factors).

For each model, we tested the proportional odds assumption that the effects of region or impact group were the same, regardless of where the cut-off points were placed across the three score categories, using the nominal test and scale test functions, which use likelihood ratio tests. When this assumption was violated, we used partial proportion odds models where possible, given our data structure. Independent variables that failed the tests were examined, with scale (dispersion of latent variable) allowed to vary among levels of the dependent variable (failure of the scale test) or effects of the relevant factor assumed to be nominal rather than ordinal (failure of the nominal test).

These models do not account for the random effects of scorer or group because the scorers were divided among two separate groups, each of which only scored half of the regions. We ran cumulative link mixed models separately for each group, including scorer as a random effect to account for differences between individual scorers. The effects of group cannot be analysed as a random factor with this study design because there are only two levels. The effect of group cannot be separated from the effect of region in a single model.

We used McFadden's pseudo $R^{2}$ value $\left(\rho^{2}\right)$ to provide an indication of goodness-of-fit for all models, as recommended by Menard ${ }^{65}$. This is calculated relative to a null model using the following equation:

$$
\rho^{2}=1-\frac{\mathrm{LL}_{\mathrm{mod}}}{\mathrm{LL}_{0}}
$$

where $\mathrm{LL}_{\text {mod }}$ is the log likelihood value for the fitted model and $\mathrm{LL}_{0}$ is the log likelihood for the null model which includes only an intercept as predictor (so that every score is predicted with the same probability).

Results of this analysis are provided and discussed in the Supplementary Information (Supplementary Tables 4-9 and accompanying text).

Reporting Summary. Further information on research design is available in the Nature Research Reporting Summary linked to this article.

\section{Data availability}

Figures 2 and 3 represent scores from round 3 of a Delphi process with $n=20$ expert scorers. Medians and interquartile ranges for these scores are presented in full in Supplementary Tables 2 and 3; the raw data are shown in Extended Data Figs. 2 and 3.

Received: 23 October 2020; Accepted: 14 July 2021;

Published online: 16 August 2021

\section{References}

1. The Assessment Report of the Intergovernmental Science-Policy Platform on Biodiversity and Ecosystem Services on Pollinators, Pollination and Food Production (IPBES, 2016).

2. Potts, S. G. et al. Safeguarding pollinators and their values to human well-being. Nature 540, 220-229 (2016).

3. Chaplin-Kramer, R. et al. Global malnutrition overlaps with pollinator-dependent micronutrient production. Proc. R. Soc. B https://doi. org/10.1098/rspb.2014.1799 (2014).

4. Powney, G. D. et al. Widespread losses of pollinating insects in Britain. Nat. Commun. 10, 1018 (2019).

5. Koh, I. et al. Modeling the status, trends, and impacts of wild bee abundance in the United States. Proc. Natl Acad. Sci. USA 113, 140-145 (2016).

6. Reilly, J. R. et al. Crop production in the USA is frequently limited by a lack of pollinators. Proc. R. Soc. B 287, 20200922 (2020).

7. Aizen, M. A. et al. Global agricultural productivity is threatened by increasing pollinator dependence without a parallel increase in crop diversification. Glob. Change Biol. 25, 3516-3527 (2019).

8. Chaplin-Kramer, R. et al. Global modeling of nature's contributions to people. Science 366, 255-258 (2019).

9. Moritz, R. F. A. \& Erler, S. Lost colonies found in a data mine: global honey trade but not pests or pesticides as a major cause of regional honeybee colony declines. Agric. Ecosyst. Environ. 216, 44-50 (2016).

10. Senapathi, D., Goddard, M. A., Kunin, W. E. \& Baldock, K. C. R. Landscape impacts on pollinator communities in temperate systems: evidence and knowledge gaps. Funct. Ecol. 31, 26-37 (2017).
11. Soroye, P., Newbold, T. \& Kerr, J. Climate change contributes to widespread declines among bumble bees across continents. Science 367, $685(2020)$.

12. Woodcock, B. A. et al. Country-specific effects of neonicotinoid pesticides on honey bees and wild bees. Science 356, 1393-1395 (2017).

13. Carvell, C. et al. Bumblebee family lineage survival is enhanced in high-quality landscapes. Nature 543, 547 (2017).

14. Tonietto Rebecca, K. \& Larkin Daniel, J. Habitat restoration benefits wild bees: a meta-analysis. J. Appl. Ecol. 55, 582-590 (2017).

15. Wintermantel, D., Odoux, J.-F., Chadœuf, J. \& Bretagnolle, V. Organic farming positively affects honeybee colonies in a flower-poor period in agricultural landscapes. J. Appl. Ecol. 56, 1960-1969 (2019).

16. Dicks, L. V. et al. Ten policies for pollinators. Science 354, 975-976 (2016).

17. FAO's Global Action on Pollination Services for Sustainable Agriculture: National Initiatives (FAO, 2020); http://www.fao.org/pollination/ major-initiatives/national- initiatives/en/

18. Conservation and Sustainable Use of Pollinators CBD/COP/DEC/14/6 30 November 2018 (Convention on Biological Diversity, 2018).

19. Teichroew, J. L. et al. Is China's unparalleled and understudied bee diversity at risk? Biol. Conserv. 210, 19-28 (2017).

20. Breeze, T. D., Gallai, N., Garibaldi, L. A. \& Li, X. S. Economic measures of pollination services: shortcomings and future directions. TREE 31, 927-939 (2016).

21. Díaz, S. et al. Summary for Policymakers of the Global Assessment Report on Biodiversity and Ecosystem Services of the Intergovernmental Science-Policy Platform on Biodiversity and Ecosystem Services (IPBES, 2019).

22. Hall, D. M. \& Steiner, R. Insect pollinator conservation policy innovations at subnational levels: lessons for lawmakers. Environ. Sci. Policy $\mathbf{9 3}$ 118-128 (2019).

23. Díaz, S. et al. Pervasive human-driven decline of life on Earth points to the need for transformative change. Science 366, eaax3100 (2019).

24. Mukherjee, N. et al. The Delphi technique in ecology and biological conservation: applications and guidelines. Methods Ecol. Evol. 6, 1097-1109 (2015)

25. Kovács-Hostyánszki, A. et al. Ecological intensification to mitigate impacts of conventional intensive land use on pollinators and pollination. Ecol. Lett. 20, 673-689 (2017).

26. Kennedy, C. M. et al. A global quantitative synthesis of local and landscape effects on wild bee pollinators in agroecosystems. Ecol. Lett. 16, 584-599 (2013)

27. Basu, P. et al. Scale dependent drivers of wild bee diversity in tropical heterogeneous agricultural landscapes. Ecol. Evol. 6, 6983-6992 (2016)

28. Marques, A. et al. Increasing impacts of land use on biodiversity and carbon sequestration driven by population and economic growth. Nat. Ecol. Evol. 3, 628-637 (2019).

29. Jayne, T. S., Snapp, S., Place, F. \& Sitko, N. Sustainable agricultural intensification in an era of rural transformation in Africa. Glob. Food Security 20, 105-113 (2019).

30. Mitchell, E. A. D. et al. A worldwide survey of neonicotinoids in honey. Science 358, 109-111 (2017).

31. Woodcock, B. A. et al. Impacts of neonicotinoid use on long-term population changes in wild bees in England. Nat. Commun. 7, 12459 (2016).

32. Rundlof, $M$. et al. Seed coating with a neonicotinoid insecticide negatively affects wild bees. Nature 521, 77-80 (2015).

33. Schreinemachers, P. \& Tipraqsa, P. Agricultural pesticides and land use intensification in high, middle and low income countries. Food Policy 37, 616-626 (2012)

34. Neonicotinoid Insecticides: Use and Effects in African Agriculture: a Review and Recommendations to Policymakers (NASAC, 2019); https://nasaconline.org/en/ index.php/2020/05/26/ neonicotinoid-insecticides-use- and-effectsin-african- agriculture-a-review-and- recommendations-to-policy-makers/

35. Herrando, S. et al. Contrasting impacts of precipitation on Mediterranean birds and butterflies. Sci. Rep. 9, 5680 (2019).

36. Brookes, G. \& Barfoot, P. GM Crops: Global Socio-economic and Environmental Impacts 1996-2018 (PG Economics Ltd, 2020); https://pgeconomics.co.uk/pdf/globalimpactfinalreportJuly2020.pdf

37. Farina, W. M., Balbuena, M. S., Herbert, L. T., Gonalons, C. M. \& Vazquez, D. E. Effects of the herbicide glyphosate on honey bee sensory and cognitive abilities: individual impairments with implications for the hive. Insects 10, 354 (2019).

38. Zattara, E. E. \& Aizen, M. A. Worldwide occurrence records suggest a global decline in bee species richness. One Earth 4, 114-123 (2021).

39. Regan, E. C. et al. Global trends in the status of bird and mammal pollinators. Conserv. Lett. 8, 397-403 (2015).

40. Garibaldi, L. A. et al. Wild pollinators enhance fruit set of crops regardless of honey bee abundance. Science 339, 1608-1611 (2013).

41. Samnegård, U., Hambäck, P. A., Lemessa, D., Nemomissa, S. \& Hylander, K. A heterogeneous landscape does not guarantee high crop pollination. Proc. Biol. Sci. 283, 20161472 (2016). 
42. Groeneveld, J. H., Tscharntke, T., Moser, G. \& Clough, Y. Experimental evidence for stronger cacao yield limitation by pollination than by plant resources. Perspect. Plant Ecol. Evol. Syst. 12, 183-191 (2010).

43. Lautenbach, S., Seppelt, R., Liebscher, J. \& Dormann, C. F. Spatial and temporal trends of global pollination benefit. PLoS ONE 7, e35954 (2012).

44. Garibaldi, L. A., Aizen, M. A., Klein, A. M., Cunningham, S. A. \& Harder, L. D. Global growth and stability of agricultural yield decrease with pollinator dependence. Proc. Natl Acad. Sci. USA 108, 5909-5914 (2011).

45. Ritchie, H. \& Roser, M. Urbanization (Our World in Data, 2018); https://ourworldindata.org/urbanization

46. Hipolito, J., Boscolo, D. \& Viana, B. F. Landscape and crop management strategies to conserve pollination services and increase yields in tropical coffee farms. Agriculture Ecosyst. Environ. 256, 218-225 (2018).

47. Begotti, R. A. \& Peres, C. A. Rapidly escalating threats to the biodiversity and ethnocultural capital of Brazilian Indigenous Lands. Land Use Policy 96, 10 (2020).

48. Pirk, C. W. W., Strauss, U., Yusuf, A. A., Démares, F. \& Human, H. Honeybee health in Africa-a review. Apidologie 47, 276-300 (2016).

49. Gebremedhn, H., Amssalu, B., Smet, L. D. \& de Graaf, D. C. Factors restraining the population growth of Varroa destructor in Ethiopian honey bees (Apis mellifera simensis). PLoS ONE 14, e0223236 (2019).

50. Junge, X., Lindemann-Matthies, P., Hunziker, M. \& Schüpbach, B. Aesthetic preferences of non-farmers and farmers for different land-use types and proportions of ecological compensation areas in the Swiss lowlands. Biol. Conserv. 144, 1430-1440 (2011).

51. Lee, H., Sumner, D. A. \& Champetier, A. Pollination markets and the coupled futures of almonds and honey bees: simulating impacts of shifts in demands and costs. Am. J. Agric. Econ. 101, 230-249 (2019).

52. Rucker, R. R., Thurman, W. N. \& Burgett, M. Colony collapse and the consequences of bee disease: market adaptation to environmental change. J. Assoc. Environ. Resour. Econ. 6, 927-960 (2019).

53. Breeze, T. D. et al. Linking farmer and beekeeper preferences with ecological knowledge to improve crop pollination. People Nat. 1, 562-572 (2019).

54. Hall, D. M. \& Martins, D. J. Human dimensions of insect pollinator conservation. Curr. Opin. Insect Sci. 38, 107-114 (2020).

55. Zommers, Z. et al. Burning embers: towards more transparent and robust climate-change risk assessments. Nat. Rev. Earth Environ. 1, 516-529 (2020).

56. Duijm, N. J. Recommendations on the use and design of risk matrices. Saf. Sci. 76, 21-31 (2015).

57. Peace, C. The risk matrix: uncertain results? Policy Pract. Health Saf. 15 131-144 (2017).

58. Morgan, M. G. Use (and abuse) of expert elicitation in support of decision making for public policy. Proc. Natl Acad. Sci. USA 111, 7176-7184 (2014).

59. Regan, H. M., Colyvan, M. \& Burgman, M. A. A taxonomy and treatment of uncertainty for ecology and conservation biology. Ecol. Appl. 12, 618-628 (2002).

60. FAOStat (FAO, 2017); http://www.fao.org/faostat/en/\#data

61. Regional Report for Africa on Pollinators and Pollination and Food Production UNEP/CBD/COP/13/INF/36 (Convention on Biological Diversity, 2016).

62. Sutherland, W. J., Fleishman, E., Mascia, M. B., Pretty, J. \& Rudd, M. A. Methods for collaboratively identifying research priorities and emerging issues in science and policy. Methods Ecol. Evol. 2, 238-247 (2011).

63. Wickham, H. ggplot2. R v.4.0.0 https://ggplot2.tidyverse.org/ (2016).

64. Christensen, R. H. B. ordinal. R v.4.0.3 http://www.cran.r-project.org/ package $=$ ordinal/ (2018)
65. Menard, S. Applied Logistic Regression Analysis (SAGE Publications, 2002).

66. Hill, R. et al. Biocultural approaches to pollinator conservation. Nat. Sustain. 2, 214-222 (2019)

\section{Acknowledgements}

We thank the following people who took part in an early scoping of this exercise during writing of the IPBES Pollination Assessment, helping to define the parameters: T. Aneni, B. Brosi, S. Cunningham, M. del Coro Arizmendi, C. Eardley, A. Espindola, M. Espirito Santo, B. Freitas, N. Gallai, K. Goka, D. Inouye, C. Jung, E. Kelbessa, P. Kwapong, X. Li, A. Lopes, D. Martins, C. Maus, G. Nates, R. Paxton, J. Pettis, J. Quezada-Euan, J. Settele, H. Szentgyorgyi, H. Taki, R. Veldtman and S. Wiantoro. We thank S. Barnsley and L. Blackmore, who supported the discussion groups as note-takers during the workshops. We are grateful to T. Balcombe and C. Vidler for planning and organizing the workshop and to J. Huang for support with the figures. We thank the University of Reading's Building Outstanding Impact Support Programme for supporting S.G.P., T.D.B. and D.S. and the workshop attendees. We would like to warmly thank IPBES for having dedicated its first assessment report to the important issue of pollinators and for having brought an unprecedented level of awareness on their importance and loss worldwide. This paper builds on some of the concepts from the IPBES pollination assessment and was, in many ways, inspired by that assessment. The views expressed here, however, represent the individual views of the authors. L.V.D. is funded by the Natural Environment Research Council (grant nos NE/N014472/1 and 2). A.K.-H. was supported by the National Research, Development and Innovation Office (FK 123813).

\section{Author contributions}

L.V.D. conceived and designed the study. L.V.D and T.D.B. contributed equally to data collection, analysis and writing the paper. S.G.P. and H.T.N. convened the expert panel. S.G.P., D.S., T.D.B., H.T.N. and L.V.D. designed, organized and ran the workshop. L.V.D., T.D.B., H.T.N., A.J., M.A.A., P.B., D.B., L.G., L.A.G., B. Gemmill-Herren, B. G. Howlett, V.L.I.-F., S.D.J., A.K.-H., Y.J.K., H.M.G.L., T.L., C.L.S., A.J.V. and S.G.P. contributed to all rounds of scoring and discussion and commented on and edited the final manuscript. D.S. contributed to discussions and commented on and edited the final manuscript.

\section{Competing interests}

The authors declare no competing interests.

\section{Additional information}

Extended data is available for this paper at https://doi.org/10.1038/s41559-021-01534-9. Supplementary information The online version contains supplementary material available at https://doi.org/10.1038/s41559-021-01534-9.

\section{Correspondence and requests for materials should be addressed to L.V.D.}

Peer review information Nature Ecology \& Evolution thanks the anonymous reviewers for their contribution to the peer review of this work. Peer reviewer reports are available. Reprints and permissions information is available at www.nature.com/reprints. Publisher's note Springer Nature remains neutral with regard to jurisdictional claims in published maps and institutional affiliations.

(C) The Author(s), under exclusive licence to Springer Nature Limited 2021 


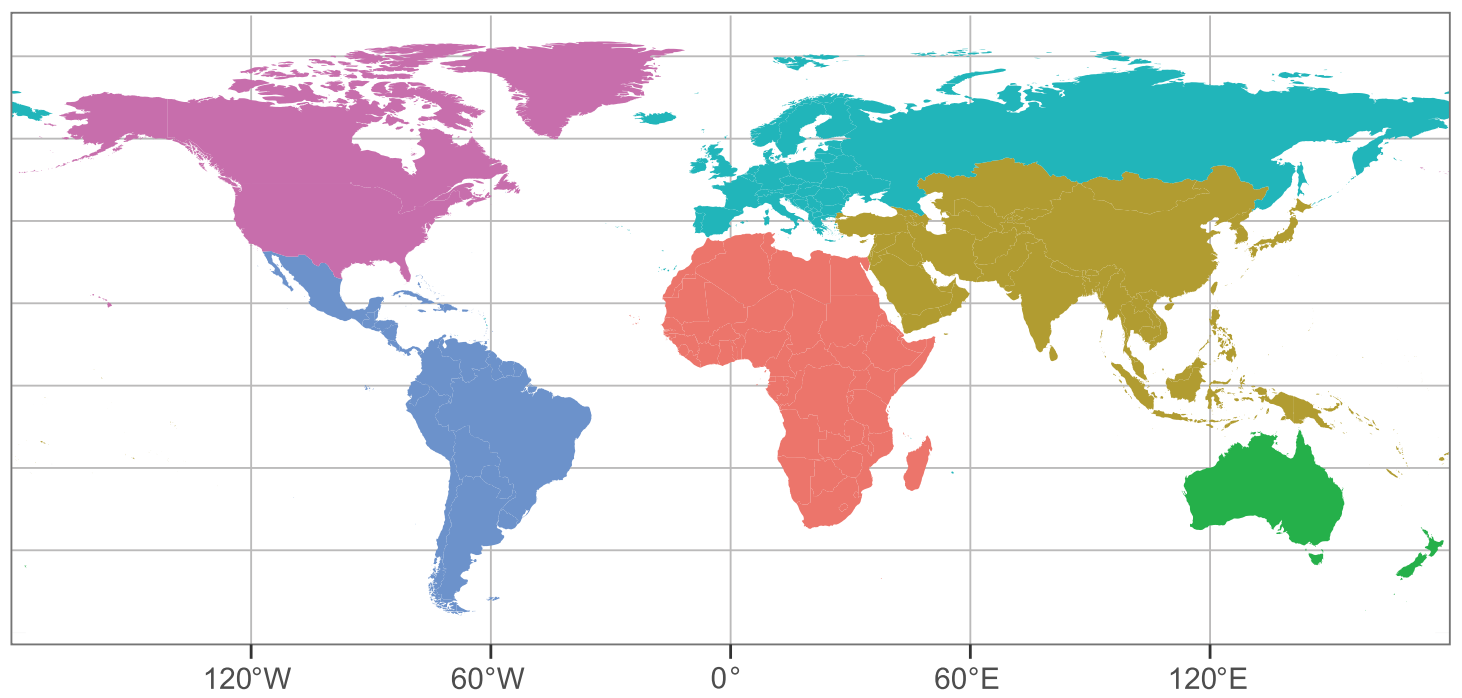

Africa

Asia-Pacific

Australia/NZ

Europe

Latin America

North America

Extended Data Fig. 1 | Definition of global regions according to biogeographical and geopolitical conditions. Definition of global regions according to biogeographical and geopolitical conditions. 
Pollinator management-

Pests \& pathogens

Pesticide use

Land management

Land cover \& configuration-

Invasive alien species.

GMOs.

Climate change

Pollinator management

Pests \& pathogens.

Pesticide use

Land management

Land cover \& configuration

Invasive alien species.

Climate change
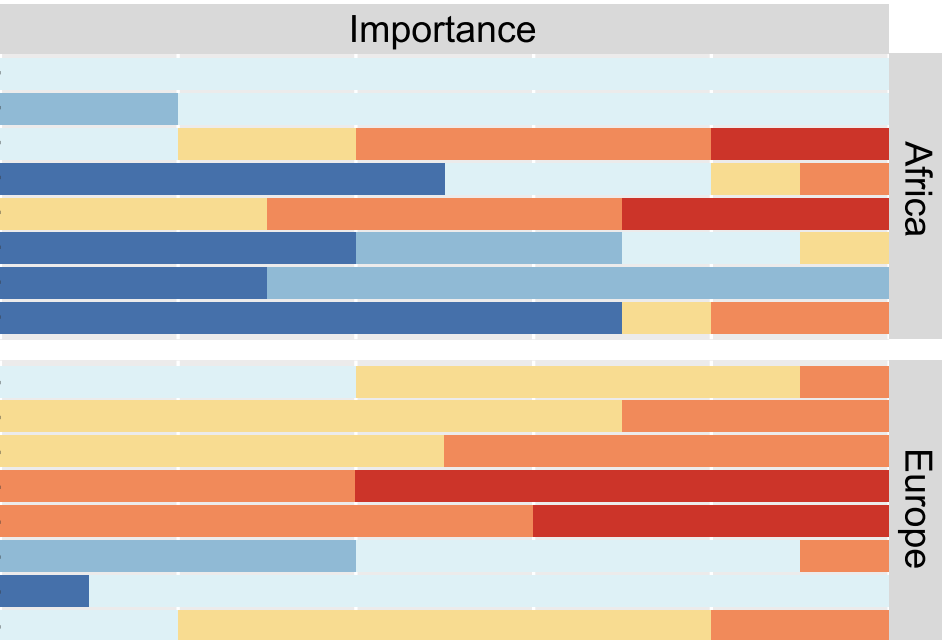

Pollinator management-

Pests \& pathogens

Pesticide use

Land management

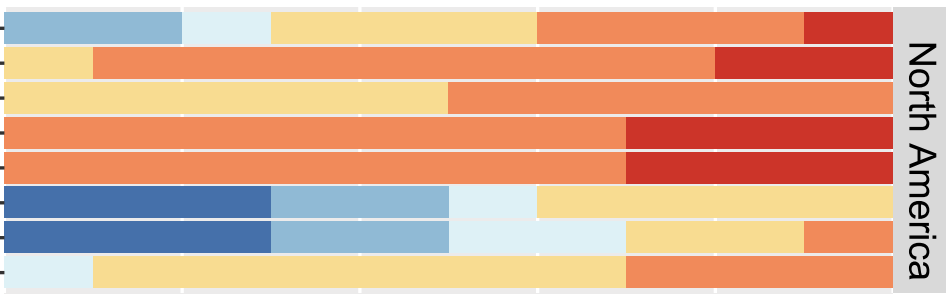

\section{Score category}

Land cover \& configuration -

Invasive alien species

GMOs

Climate change

Pollinator management

Pests \& pathogens

Pesticide use

Land management-

Land cover \& configuration.

Invasive alien species.

GMOs.

Climate change

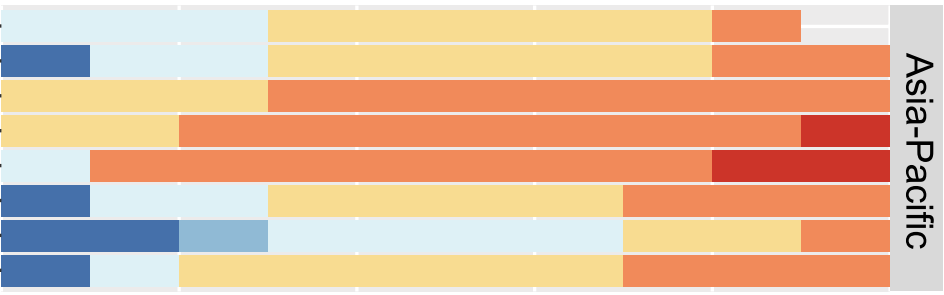

The most important

Very important

Important

A little important

Not important

Unknown

Pollinator management-

Pests \& pathogens

Pesticide use

Land management-

Land cover \& configuration.

Invasive alien species

GMOs

Climate change

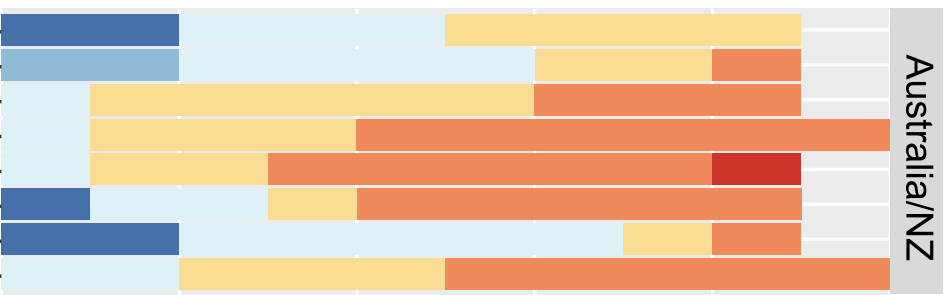

Pollinator management-

Pests \& pathogens

Pesticide use-

Land management

Land cover \& configuration-

Invasive alien species-

GMOs.

Climate change-

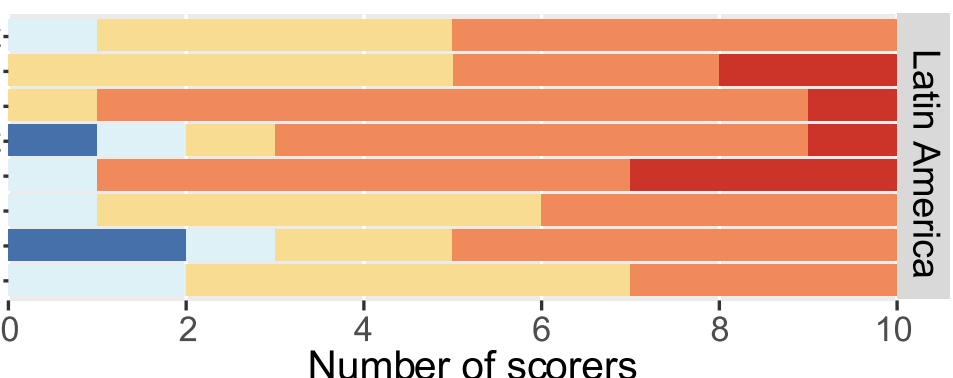

Number of scorers

Extended Data Fig. 2 | Final breakdown of scoring of direct drivers by world regions and importance. Final breakdown of scoring of direct drivers by world regions and importance. 


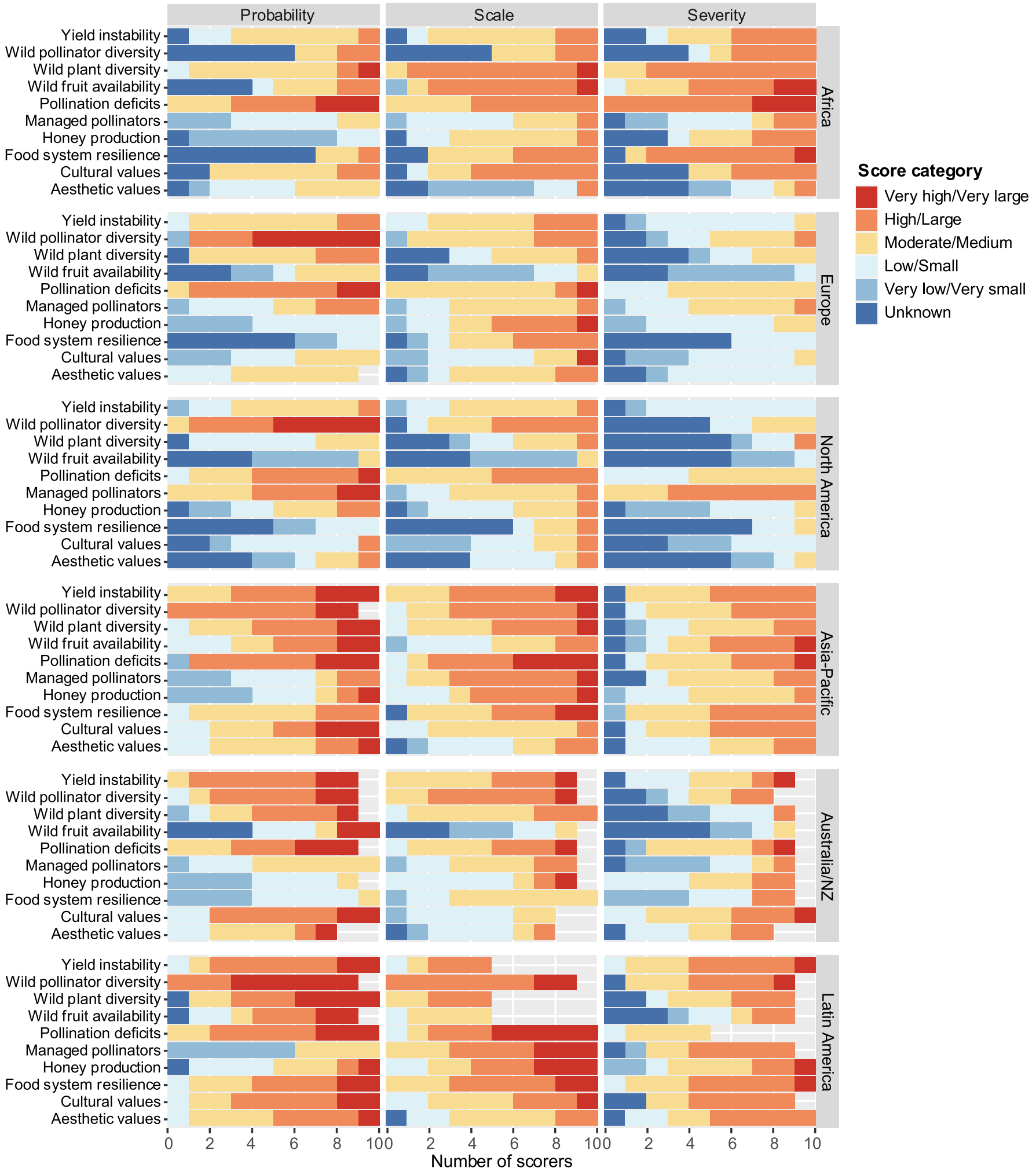

Extended Data Fig. 3 | Final breakdown of scoring of risks by world regions, impact and components of risk (probability, scale, severity). Final breakdown of scoring of risks by world regions, impact and components of risk (probability, scale, severity). 


\section{Reporting Summary}

Nature Portfolio wishes to improve the reproducibility of the work that we publish. This form provides structure for consistency and transparency in reporting. For further information on Nature Portfolio policies, see our Editorial Policies and the Editorial Policy Checklist.

\section{Statistics}

For all statistical analyses, confirm that the following items are present in the figure legend, table legend, main text, or Methods section.

n/a Confirmed

$\square$ The exact sample size $(n)$ for each experimental group/condition, given as a discrete number and unit of measurement

Х $\square$ A statement on whether measurements were taken from distinct samples or whether the same sample was measured repeatedly

$\square$ The statistical test(s) used AND whether they are one- or two-sided

Only common tests should be described solely by name; describe more complex techniques in the Methods section.

$\square$ A description of all covariates tested

$\square$ \A description of any assumptions or corrections, such as tests of normality and adjustment for multiple comparisons

$\square$ A full description of the statistical parameters including central tendency (e.g. means) or other basic estimates (e.g. regression coefficient)

$\triangle$ AND variation (e.g. standard deviation) or associated estimates of uncertainty (e.g. confidence intervals)

Х For null hypothesis testing, the test statistic (e.g. $F, t, r$ ) with confidence intervals, effect sizes, degrees of freedom and $P$ value noted

Х Give P values as exact values whenever suitable.

Х $\square$ For Bayesian analysis, information on the choice of priors and Markov chain Monte Carlo settings

$\square \bigotimes$ For hierarchical and complex designs, identification of the appropriate level for tests and full reporting of outcomes

\ $\square$ Estimates of effect sizes (e.g. Cohen's $d$, Pearson's $r$ ), indicating how they were calculated

Our web collection on statistics for biologists contains articles on many of the points above.

\section{Software and code}

Policy information about availability of computer code

Data collection Provide a description of all commercial, open source and custom code used to collect the data in this study, specifying the version used OR state that no software was used.

Data analysis Data analysis was conducted using R version 4.0.3. The fordinal\} package was used for the ordinal regression analysis presented in the Supplementary Information. Both these sources are cited in the Methods section. We have not included a code availability statement, because we have not used bespoke or custom code or mathematical algorithms, only code that is either described in these references, or commonly used for data manipulation and visualisation in $\mathrm{R}$.

For manuscripts utilizing custom algorithms or software that are central to the research but not yet described in published literature, software must be made available to editors and reviewers. We strongly encourage code deposition in a community repository (e.g. GitHub). See the Nature Portfolio guidelines for submitting code \& software for further information.

\section{Data}

Policy information about availability of data

All manuscripts must include a data availability statement. This statement should provide the following information, where applicable:

- Accession codes, unique identifiers, or web links for publicly available datasets

- A description of any restrictions on data availability

- For clinical datasets or third party data, please ensure that the statement adheres to our policy

Figures 2 and 3 represent scores from round 3 of a Delphi process with $n=20$ expert scorers. Medians and Interquartile ranges for these scores are presented in full in the Supplementary Information (Supplementary Tables 2 and 3); the raw data are shown in Extended Data Figures 2 and 3. 


\section{Field-specific reporting}

Please select the one below that is the best fit for your research. If you are not sure, read the appropriate sections before making your selection.
Life sciences
Х Behavioural \& social sciences
Ecological, evolutionary \& environmental sciences

For a reference copy of the document with all sections, see nature.com/documents/nr-reporting-summary-flat.pdf

\section{Behavioural \& social sciences study design}

All studies must disclose on these points even when the disclosure is negative.

Study description

Research sample

Sampling strategy

Data collection

Timing

Data exclusions

Non-participation

Randomization
This study is an expert elicitation, following a modified Delphi process. 20 purposively selected participants discussed evidence and anonymously submitted scores reflecting their judgement on 10 impacts of pollinator decline on human well-being, and eight drivers of pollinator decline, in a three-round iterative process.

Participants were 20 purposively selected pollinator and pollination experts, all authors of the paper (therefore not research subjects, but collaborators). Thirteen of the 20 authors were also authors of the IPBES global pollination assessment, mostly nominated by their respective national governments, and the team had a relatively balanced gender ratio of 11 men : 9 women.

The set of 20 pollination experts was purposively selected to cover the range of necessary expertise, including biodiversity science, economics, social science and indigenous and local knowledge, and to ensure that the main global regions were each represented by at least two scorers either originating from or mainly working in that region.

Data were recorded by individual participants in an Excel spreadsheet on their own laptops, and transferred to a master spreadsheet by author Tom Breeze, during the workshop. Quality control involved cross-checking individual spreadsheets against the master dataset, in randomly selected data points and summary data, in both $\mathrm{R}$ and Excel.

Data were collected from October to November 2017, in the year following publication of the IPBES pollinators and pollination assessment.

No data were excluded from analysis.

No participants dropped out.

Participants were allocated into discussion groups based on their regional expertise.

\section{Reporting for specific materials, systems and methods}

We require information from authors about some types of materials, experimental systems and methods used in many studies. Here, indicate whether each material, system or method listed is relevant to your study. If you are not sure if a list item applies to your research, read the appropriate section before selecting a response.

Materials \& experimental systems

\begin{tabular}{|c|c|}
\hline$n / a$ & Involved in the study \\
\hline Х & $\square$ Antibodies \\
\hline X & $\square$ Eukaryotic cell lines \\
\hline$\bigotimes$ & $\square$ Palaeontology and archaeology \\
\hline Х & $\square$ Animals and other organisms \\
\hline$\bigotimes$ & $\square$ Human research participants \\
\hline$\bigotimes$ & $\square$ Clinical data \\
\hline$\bigotimes$ & $\square$ Dual use research of concern \\
\hline
\end{tabular}

\begin{tabular}{l|l} 
Methods \\
\hline n/a & Involved in the study \\
$\square$ & $\square$ ChIP-seq \\
$\searrow$ & $\square$ Flow cytometry \\
$\square$ & $\square$ MRI-based neuroimaging
\end{tabular}

